\title{
Contribuições das geociências à prática de educação ambiental em escola da área rural em Alegrete, RS
}

\author{
JAQUELINE FLAIN MORAES \\ Edgardo Ramos MedeIROS
}

\section{RESUMO}

O presente trabalho trata do levantamento dos aspectos físicos (geologia, geomorfologia, entre outros e dos processos erosivos) com base em levantamentos de campo e cartas topográficas da região oeste do Rio Grande do Sul, mais especificamente dos municípios de São Francisco de Assis, Manoel Viana e Alegrete. Por apresentar sérios problemas de erosão, desmatamento ciliar e assoreamento de drenagens, foi elaborada uma carta clinográfica para determinar as áreas de maior/menor fragilidade e áreas sucetíveis a processos erosivos que, posteriormente, foram plotados na maquete da área, juntamente com outros dados como litologia, drenagem, vegetação, relevo, uso e ocupação do solo. Paralelamente ao levantamento físico da área, foram aplicados questionários à comunidade escolar, para coletar informações referentes a projetos de educação ambiental e, aos moradores locais a fim de diagnosticar o perfil sócio-econômico e principais problemas, bem como técnicas de plantio, conservação do solo, produção e utilização de produtos químicos, entre outros. Como etapa final, e objetivo principal do trabalho, foram ministradas palestras nas escolas, (uma de cada município) com o auxilio da maquete, como recurso didático para despertar o interesse em participar. Foram abordados os principais tipos de degradações ambientais e possíveis soluções, dando ênfase à problemática local. 


\section{ABSTRACT}

The present work describes the physical aspects (geology, geomorphology and other) and of the erosive processes, based on direct observation in the field and in the topographical maps of the area localized in the west of Rio Grande do Sul state, more specifically of the municipal districtis of São Francisco of Assis, Manoel Viana and Alegrete.

In consequence of urosion problms, ciliary deforestation and sediments accumulation of drainages, a climate map was elaborated, that associated to the characteristics lithological and of vegetation and other, it allowed to determine adult's areas or smaller fragility to the erosive processes.

These data together with the one of relief, drainage vegetation, as well as of use and occupation of the soil, they were plotted in an area maquette. Parallel to the physical observation of the area, they were applied questionnaires to the school community, to collect information to projects of environmental education and, to the local residents in order to diagnose the profile economical partner and main problems, as well as planting techniques, conservation of thesoil, production and use of chemical products, among others.

As final stage and principal aim of the work, lectures were supplied at the schools (one of each municipal district). The principal kinds of environmental degradation and possible solutions were approached, giving emphasis to the local problem.

\section{INTRODUÇÃO}

Atualmente, com a crescente destruição dos recursos naturais e do meio ambiente, torna-se, cada vez mais, necessária a integração do homem com a natureza.

O homem utiliza tudo o que a natureza oferece de forma indiscriminada, alterando o equilíbrio dos ecossistemas, onde todos os elementos estão interligados, seja de forma direta ou indireta.

Quando uma dessas relações rompe-se, ou um dos elementos desaparece, determina, de um modo geral, alterações nas demais.

Muitas vezes, a ambição, a necessidade ou ainda compromissos assumidos, face as circunstâncias, impulsionam o homem a auferir rendas imediatas, cujas formas comprometem o meio ambiente, não interessando os efeitos negativos que possam gerar. 
Entretanto, essa utilização, que deveria ser racional, está tomando rumos perigosos de destruição, pelo desequilíbrio que o homem impõe ao meio ambiente, quando atua nas atividades de produção.

Assim, o solo, a vegetação, a água e o ar fazem parte deste ambiente e como tanto, devem ser tratados de maneira equilibrada e respeitosa, sob pena de ocasionar rompimento nas suas interrelações, o que, conseqüentemente, imporá sérias restrições, algumas irreversíveis, aos seres vivos ali existentes.

Como exemplos pertinentes a esta afirmação pode-se citar os processos erosivos, tão significativos no oeste-sudoeste gaúcho e no noroeste paranaense. Obviamente, não se pode imputar responsabilidades, por tal situação, única e exclusivamente a maneira, geralmente indiscriminada, que o homem faz destas áreas, mas, por outro lado, não se pode deixar de incriminá-lo de ser o responsável pela aceleração de processos naturais.

Estes processos erosivos, anualmente, são responsáveis pelo carreamento, pelas águas, de milhões de toneladas de solos e de litologias. Só no Rio Grande do Sul, segundo Vieira e Rangel (1993), mais de cem milhões de toneladas de terras férteis são deslocadas para as áreas terminais do sistema hidrográfico. Os impactos ambientais, sociais e econômicos decorrentes, podem ser observados pela destruição da biodiversidade, tanto da flora quanto da fauna, bem como pela diminuição da disponibilidade de recursos hídricos em função da contaminação e do assoreamento, o que está tomando grandes proporções. Todos esses fatores, associados à perda da produtividade agrícola, trazem consigo a perda social, representada, entre outras, por migrações de famílias para as zonas urbanas, que por sua vez não têm condições de oferecer serviços a estas massas de migrantes.

Os processos de geração dos "campos de areia" (Veiga et alii, 1987) ou de "arenização" (Suertegaray, 1987), também erroneamente conhecidos como processos de "desertificação", comuns e significativos nos municípios de Manuel Viana, Alegrete, São Francisco de Assis, entre outros, representam, com muita clareza, esta degradação ambiental decorrente, em especial, do mau uso do solo.

A educação ambiental no sistema escolar torna-se imprescindível, pois a escola exerce influência na transformação social, quer através da aquisição de conhecimentos, quer na mudança de atitudes, o que contribui para uma nova visão e adoção de novas posturas frente ao meio ambiente. 
Dentro deste contexto, o objetivo geral do trabalho, foi levar aos alunos das séries finais do ensino fundamental da Escola Estadual de $1^{\circ}$ Grau Barros Cassal, Escola Municipal de Ensino Fundamental Costa Leite, ambos no município de Alegrete e na Escola Estadual de Educação Básica Manoel Viana e CAMAVI (Clube da Árvore de Manuel Viana), o conhecimento da realidade ambiental de suas respectivas regiões.

\section{METODOLOGIA}

Optou-se por trabalhar educação ambiental, na região de São Francisco de Assis, Manuel Viana e Alegrete, por apresentar sérios problemas de erosão, agravados pelo mau uso do solo.

Inicialmente, foi realizada uma revisão bibliográfica sobre a temática proposta, ficando patente a existência de informes sobre aspectos físicos da área, enquanto que sobre aspectos sócioeconômicos e educacionais são, praticamente, inexistentes.

Foram realizadas seis saídas de campo, onde se levantou dados sobre os aspectos físicos (geologia, geomorfologia, processos erosivos, entre outros) da área propriamente dita. Como base nos levantamentos de campo foram utilizadas as cartas topográficas na escala 1: 50.000, de Manuel Viana (folha SH. 21-X-D-IV1), São Francisco de Assis (folha SH. 21-X-D-IV-2) e Passo Novo (folha SH. 21-X-C-IV-2), da DSG Exército-Brasil e datadas de 1978. Como equipamento de campo utilizou-se bússola tipo Brumpton, GPS de alta precisão (12 satélites), usado especialmente na delimitação da área, martelo de geólogo e trena para algumas medidas de voçorocas.

Concomitante ao levantamento físico, foi elaborado e aplicado questionários buscando conhecer, em especial, a comunidade escolar objetivando a coleta de informações referentes a projetos de educação ambiental desenvolvidos na escola e outros. Também, foram aplicados questionários aos moradores locais, objetivando conhecer as características sócio-econômicas e principais problemas relacionados à área.

Foram determinadas e classificadas a maior/menor fragilidade e as áreas suscetíveis a processos erosivos, através de uma carta clinográfica elaborada na escala 1: 50.000, utilizando-se das cartas topográficas citadas acima, que serviu de embasamento para que esses dados fossem, posteriormente plotados na maquete.

Utilizando o estabelecido por De Biasi (1992), definiuse a seguinte classificação, como demonstra o quadro: 


\begin{tabular}{|c|c|}
\hline CLASSES & DECLIVIDADE \\
\hline 1 & 0 a $2 \%$ \\
\hline 2 & 2 a $5 \%$ \\
\hline 3 & 5 a $12 \%$ \\
\hline 4 & 12 a $30 \%$ \\
\hline 5 & $>30 \%$ \\
\hline
\end{tabular}

Quadro 1. Classes de Declividade

Fonte: De Biasi, 1992.

Montagem: Moraes, Jaqueline Flain.

De conhecimento dos aspectos físicos foi construída uma maquete da área (680 km² aproximadamente) (Figura 1), a partir das cartas topográficas da área. A escala horizontal de 1: 50.000 , foi ampliada para 1:37.500 e a vertical para 1:4.000. Foram destacadas as principais áreas degradadas e as suscetíveis a degradação, baseando-se na carta clinográfica, e nos principais tipos litológicos. As drenagens, a vegetação, o relevo, uso e ocupação do solo que foram mapeados através de cartas topográficas da área e observações in loco.

Como etapa final e objetivo principal do trabalho, foram ministradas palestras sobre Educação Ambiental, nas seguintes escolas: Escola Municipal de Ensino Fundamental Costa Leite, Escola Estadual de $1^{\circ}$ Grau Barros Cassal, Escola Estadual de Educação Básica "Manuel Viana" e CAMAVI, onde foram abordados os principais tipos de poluição com sugestões sobre possíveis soluções, dando ênfase para a problemática local.

\section{LOCALIZAÇÃO DA ÁREA}

A área localiza-se no oeste do Rio Grande do Sul, tendo como limite norte a latitude da sede do município de Manoel Viana; a oeste o distrito de Passo Novo (Município de Alegrete); ao sul a latitude que passa pela Escola Agrotécnica Federal de Alegrete e a leste o distrito de Jacaquá (município de São Francisco de Assis) posicionando-se entre as latitudes $29^{\circ} 34^{\prime} 13^{\prime \prime}$ e $29^{\circ} 45^{\prime} 00^{\prime \prime} \mathrm{S}$ e as longitudes $55^{\circ} 10^{\prime} 42^{\prime \prime}$ e $55^{\circ} 34^{\prime} 35^{\prime \prime} \mathrm{W}$.

Geologicamente, situa-se, na quase totalidade, sobre um dos quatro compartimentos geológico-geomorfológico do nosso 
estado, denominada Depressão Periférica. A parte noroeste da área, imediatamente ao norte da calha do rio Ibicuí, bem como uma estreita faixa à leste da mesma, posicionam-se sobre rochas vulcânicas do Planalto Meridional. Cabe aqui salientar que, as cotas existentes nessa área dita de planalto, não correspondem ao que é definido como planalto, por Guerra (1989), para descrições morfológicas: "São terras situadas acima dos 200 metros, cuja superfície seja relativamente plana".

Até o presente momento não se tem outra classificação geomorfológica para esta área do Estado. Talvez, possa fazer parte da chamada "Cuesta de Haedo" (Müller F, 1970).

\section{PRÁTICA DE EDUCAÇÃO AMBIENTAL:MAQUETE REPRESENTATIVA} DO RELEVO DA REGIÃO DE MANOEL VIANA E ALEGRETE - RS

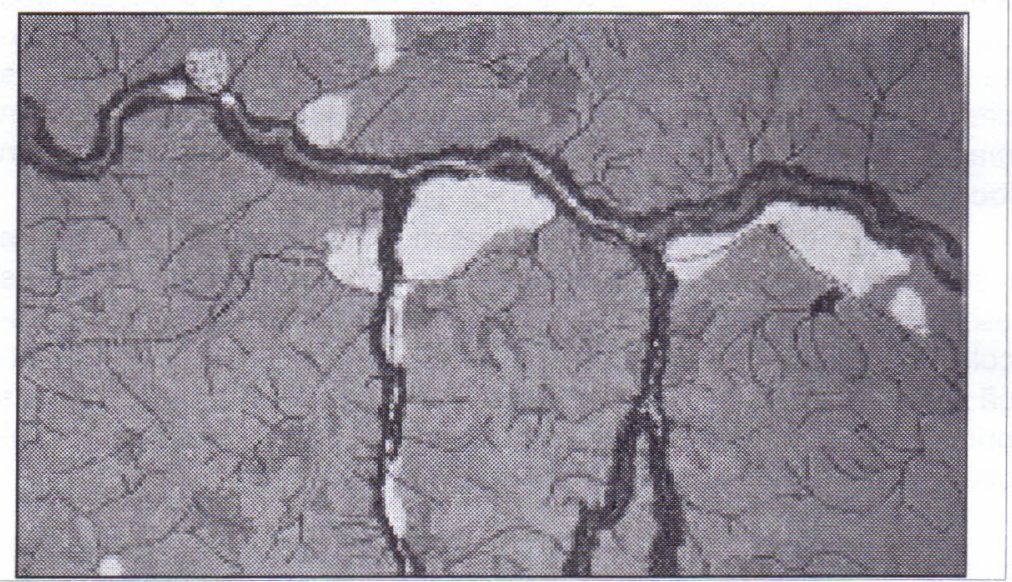

Fig. 1. Maquete da área de estudo Autor: Moraes, Jaqueline Flain.

\section{ASPECTOS FÍSICOS E NATURAIS}

\section{Geologia}

Esta região centro-oeste do Estado do Rio Grande do Sul, situada, em sua maior parte, ao sul do Planalto Meridional do Brasil, constitui-se numa faixa larga de sedimentos, com cerca de mais de $200 \mathrm{~km}$ no sentido leste-oeste e aproximadamente $50 \mathrm{~km}$ no sentido norte-sul, denominada Depressão Periférica do Rio Gran- 
de do Sul. Esta faixa, na altura da cidade de Manoel Viana, a oeste, inflete para sul em direção a Santana do Livramento, Bagé e Candiota e para o norte, em direção a Unistalda.

Trata-se de uma importante área sedimentar, rebaixada topograficamente em relação ao Planalto, ao norte e ao Escudo SulRio-grandense, ao sul. Apresenta algumas características litológicas e geomorfológicas distintas entre o seu centro-oeste e o centro-leste, de tal forma que determinam usos e ocupações diferentes.

As partes sul desta faixa constituem-se nas áreas de exposição dos sedimentos mais antigos da Bacia do Paraná, enquanto que as partes nortes expõem as mais jovens. Por outro lado, essa mesma depressão, no espaço entre o município de Santa Maria, no centro do estado e o oeste-sudoeste, especialmente numa faixa compreendida entre a escarpa do Planalto, até cerca de 10 - 15 $\mathrm{km}$ ao sul, mostra-se em parte, recoberta por sedimentos pós-derrames vulcânicos da Bacia do Paraná. Pode-se dizer que se trata da área do estado do Rio Grande do Sul mais suscetivel a processos erosivos, o que Ihe imprime característica de área de elevado risco ambiental.

$\mathrm{Na}$ realidade, esta área recebeu em épocas passadas (cretácio-terciário) e continua recebendo o aporte de sedimentos oriundos da alteração e erosão das rochas do Planalto, constituídas por seqüências sedimentares arenosas (Formação Botucatu) e vulcânicas da Formação Serra Geral.

Estes sedimentos depositados a partir do cretácio superior (?), são, possivelmente, correlacionáveis com os sedimentos das Formações Caiuá e Bauru, nos estados do Paraná e São Paulo, Formação Tupanciretã no Rio Grande do Sul e com as seqüências pós-vulcânicas presentes, principalmente, no oeste uruguaio. Ocupam hoje, nas áreas mais próximas à cidade de Santa Maria, os interflúvios, o que lhe impõem um caráter não contínuo na sua distribuição. Esta característica, à medida que se vai em direção a oeste, altera-se para contínua e passa a apresentar uma grande distribuição em superfície.

A distribuição contínua e significativa mais à oeste do estado do Rio Grande do Sul, possivelmente esteja relacionada ao soerguimento, do tipo anticlinal, comprovado pelo padrão de drenagem existente, bem como pelo alçamento de litologias mesozóicas na faixa compreendida entre o norte de Dom Pedrito e que se estende em direção noroeste, até a altura de Quaraí, acompanhando grosseiramente o limite político Brasil-Uruguai. A partir de Santana do 
Livramento, onde o contato litológico basalto-arenito posiciona-se a cerca de $270 \mathrm{~m}$, a estrutura mergulha com relativa suavidade (aproximadamente $10^{\circ}$ ), fazendo com que o mesmo contato basalto-arenito posicione-se, na cidade de Quarai, $100 \mathrm{~km}$ a noroeste, em cerca de $110 \mathrm{~m}$, apresentando um desnivel de cerca de $160 \mathrm{~m}$. Segundo Müller $F^{\circ}(1970)$ constitui a chamada Cuesta de Haedo.

Quanto ao condicionamento geológico das áreas mais suscetíveis a processos erosivos no centro-oeste-sudoeste do estado do Rio Grande do Sul, pode-se definir duas situações perfeitamente claras e distintas, posteriores ao vulcanismo da Serra Geral, que recobrem as Formações Rosário do Sul, Santa Maria e Botucatu.

A primeira e mais significativa área é que se situa nos municípios de São Francisco, Manuel Viana, Alegrete e Cacequi. Mostra duas seqüências sedimentares arenosas e areno conglomeráticas denominas por Medeiros et alii, (1995) de Seqüências São João e Cerro do Tigre,respectivamente e de idade pósvulcanismo da Bacia do Paraná.

A ocorrência destas duas seqüências litológicas tornase praticamente contínua, ocupando cotas nitidamente superiores aos basaltos.

A seqüência inferior, Cerro do Tigre, é caracterizada litológicamente como arenosa e areno-conglomerática. A mineralogia é predominantemente quartzosa, com a presença de grãos de calcedônia alterados. Os sedimentos são unidos basicamente por cimento ferruginoso, o que determina a cor vermelho-amarelada, com tonalidades variadas. Salvo patamares isolados, trata-se de uma seqüência bastante friável. Estes patamares, em função da presença de cimento silicoso, determinam, com freqüência, a presença de morros testemunhos de topo plano, este vinculado à estratificação paralela, que junto com a acanalada, constituem as estruturas mais conspícuas da rocha, exemplificados pelo próprio Cerro do Tigre. Um aspecto importante, em especial nas áreas mais a oeste, é o padrão de alteração, que determina o aparecimento de grande quantidade de blocos e matacões ( $<1,5 \mathrm{~m}$ de diâmetro) tombados nas encostas por gravidade ou arrasto por torrente.

As relações de contato com o basalto, exceto em dois ou três, afloramentos, onde é nítido, está totalmente encoberto especialmente pela topografia existente, bem como pela ausência de sondagens na área.

A espessura da seqüência, baseada nas relações topográficas, não é menor que 60 metros. 
A seqüência superior, denominada de São João, de possível idade terciária, assenta discordante e de modo erosivo sobre a Seqüência Cerro do Tigre; muitas vezes avançando diretamente sobre os basaltos mais em direção a oeste. Distribui-se de maneira mais contínua, sendo bem mais expressiva, em superfície, que a seqüência inferior.

Litológicamente, é constituída por sedimentos arenosos, e às vezes irregularmente conglomeráticos, cuja mineralogia predominante é quartzosa, com fragmentos grosseiros constituído por grânulos e seixos de calcedônia, quartzo leitoso e enfumaçado, vesículas alteradas de basalto, oriundos da Seqüência Cerro do Tigre.

A presença de estruturas limita-se, normalmente, aos níveis texturalmente mais grosseiros da seqüência, sendo poucas e mal preservadas. Estão representadas por estratificações cruzadas de baixo ângulo com sets curtos. Nos níveis arenosos superiores, a presença das mesmas só é visualizada quando há maior concentração de óxido de ferro, o que localmente preserva a integridade da estrutura. A sua constituição litológica, francamente quartzosa e a quase total ausência de cimento ferruginoso, empresta à rocha um caráter de elevada friabilidade. A espessura é variável podendo atingir mais de 30 metros.

Essa seqüência mostra-se mais suscetível à erosão, em especial à erosão em sulcos, responsável pelo aparecimento de grandes sistemas de voçorocas, que podem ser visualizadas em toda a área.

\section{Geomorfologia}

Geomorfológicamente, Segundo Medeiros et alii (1989), a área é constituída por três compartimentos geomorfológicos:

a) Planície aluvial diferenciada em um sedimento pleistocênico e outro recente;

b) Uma extensa área de coxilhas e cerros (colinas) com baixa energia de relevo;

c) Relevos tabulares, que são cerros mesetiformes, correspondentes a uma superfície de erosão, em cotas que variam entre 160 e 190 metros.

As áreas da planície aluvial ocupam as terras mais planas, principalmente a faixa central no sentido leste - oeste, que margeiam o rio Ibicuí e arroios da região. Os solos hidromórficos, 
que se originam nas planícies de inundação, são utilizados, principalmente, para o plantio de arroz.

A topografia de coxilhas predomina no total da área, apresentando-se de forma convexa alongada, aparentando um relevo relativamente suave.

Mais especificamente na porção centro sul da área, ocorre a presença dos morros testemunhos, geralmente de topo plano, em função do alto grau de cimento silicoso/ferruginoso, que dá maior resistência aos processos erosivos, sendo, portanto, o responsável pela camada mantenedora desse tipo de relevo.

Segundo Suertegaray (1995), a área mostra-se como uma paisagem extremamente frágil derivada de um paleoambiente semi-árido ou semi-úmido estepário que, mais recentemente, sofreu umidificação. Esta umidificação, por sua vez, foi suficiente para permitir o surgimento, nas áreas mais úmidas, sejam elas os vales ou as vertentes de encostas abrigadas, de uma vegetação arbórea: a mata de galeria ou a mata de encosta. Porém, este mesmo clima foi insuficiente para mascarar e/ou eliminar os vestígios da paisagem pré-modema. Daí advém sua fragilidade:uma paisagem em processo de constituição pedogenética e de vegetação recente.

\section{Solo}

De acordo com Azevedo e Kaminski (1995), a região dos núcleos de arenização está inclusa, principalmente, na unidade de mapeamento Cruz Alta (latossolo vermelho escuro, com ocorrência de areias quartzosas, mas também de solos podzólicos das unidades São Pedro e Santa Maria). As unidades possuem em comum perfis profundos, textura areia e areia franca nos horizontes superficiais. Nos horizontes subsuperficiais, a textura se mantém arenosa nas areias quartzosas, havendo um aumento suave na percentagem de argila no B do latossolo, passando a textura para franca arenosa, enquanto no $\mathrm{B}$ dos podzólicos há um aumento abrupto da argila, passando a textura para franca argilo arenosa. Possui forte limitação natural quanto à fertilidade e alta suscetibilidade à erosão, devido à pobreza de bases no material do qual se originaram e em razão de sua granulometria grosseira.

Os solos originados dessas formações arenosas, apresentam um perfil granulométrico que dificulta a formação de unidade de estrutura. Os teores de argila oscilam entre 6 e $12 \%$ e a acumulação de matéria orgânica é muito pequena, da ordem de 0,1 à $0,7 \%$. 
Isso Ihes confere um caráter extremamente débil de resistência aos processos erosivos. Por outro lado, os baixos teores de argila e matéria orgânica imprimem propriedades físico - químicas que se refletem na retenção dos nutrientes essenciais ou das substâncias portadoras desses em níveis muitos baixos ou insuficientes. Também, o armazenamento de água torna-se difícil, provocando déficit hídricos mesmo em curtos períodos de estiagem. Aliando-se, ainda, a ocorrência de vento e má distribuição das chuvas, apesar da elevada precipitação média anual $(1.400 \mathrm{~mm})$, criam-se as condições para o aparecimento dos processos erosivos.

Já para Medeiros et alii (1995), contrariamente ao que é colocado por Azevedo \& Kaminski (1995), a presença de solo limitase, em geral, às planícies de inundação das drenagens presentes na área. Nas demais situações, nas coxilhas e/ou nos morros, o solo existente limita-se a um tênue horizonte orgânico.O que é considerado, pelos autores anteriores, talvez como horizonte $\mathrm{B}$ e $\mathrm{C}$, na realidade faz parte da Seqüência São João com seus sedimentos arenosos. O que leva a tal afirmação, segundo Medeiros et alii (1995), é a presença não freqüente de estruturas sedimentares como estratificação/laminação, às vezes cruzadas de baixo ângulo, visualizadas, em especial, nos flancos internos de voçorocas.

Os processos de ravinamento e voçorocamento constituem, na área, os elementos desencadeadores dos "campos de areia" (Veiga et alii, 1987). Uma vez rompido o equilíbrio do substrato rochoso, quer pelo superpastoreio, quer pela lavração em especial, o solo/rocha vai sendo paulatinamente desagregado pelo contínuo pisoteio do gado e pelo impacto das gotas de chuva, os quais vão lentamente sendo transportados pelo escoamento superficial. Durante os fortes aguaceiros, o escoamento da água entre os tufos de gramíneas fixos no solo parcialmente exposto, dá origem a pequeninas ravinas que se alargam e se aprofundam progressivamente, formando, na sua base, diminutos cones de dejeção de areia lavada que, gradativamente, levam o pasto rarefeito encosta abaixo.

Merece destaque o enfoque dado por Penteado (1974), que diz:

\footnotetext{
"As gotas caindo, atingem uma velocidade limite, tanto maior quanto mais grossas forem, e sua energia cinética cresce com o quadrado de sua velocidade exercendo, no solo verdadeiro bombardeamento".
} 
As conseqüências do ataque sofrido pelo solo estão na dependência de determinados fatores de ordem físico-biológica, entre os quais destacam-se: cobertura vegetal, declividade, textura e coesão.

\section{Vegetação}

A característica mais notável desta região é a grande predominância de formações campestres, que se constituem na cobertura vegetal original e dominante, recobrindo uma topografia de coxilha em algumas áreas entremeada com maior ou menor intensidade de pequenos arbustos.

As matas nativas recobrem, em geral as vertentes dos morros testemunhos, bem como as faixas que acompanham as margens dos arroios Miracatu, São João e Divisa, e com maior densidade ao longo do curso do rio lbicuí tratando-se, nos dois casos de habitat favorecido por um suprimento mais regular de água.

Segundo Vieira (1984)

"A cobertura florestal exerce importante influência nos solos, impedindo a ação dos processos erosivos, ravinamentos, voçorocamentos e a desertificação que no Rio Grande do Sul, atinge diversas áreas como São Francisco de Assis, Alegrete e Itaqui."

Quanto à preservação, estas são, em geral, moderadamente preservadas em especial ao longo do curso do rio Ibicuí, onde a vegetação é mais abundante. Nas demais drenagens que, localmente fazem parte da bacia maior, esta mata encontra-se representada, principalmente, por uma vegetação arbórea secundária de menor porte. Já ao longo do arroio Caraguataí, no extremo noroeste da área, ela mostra-se quase totalmente destruída.

Sob a ótica da hidrologia florestal, as matas ciliares ocupam as áreas mais dinâmicas da paisagem, tanto em termos hidrológicos, quanto em ecológicos e geomorfológicos. Estas áreas têm sido chamadas de zonas ripárias (Rodrigues \& Leitão $\mathrm{F}^{\circ}, 2000$ ). Segundos os mesmos autores, esta zona está intimamente ligada ao curso d'água, mas os seus limites não são facilmente demarcados.

Do ponto de vista ecológico, as zonas ripárias tem sido consideradas como corredores importantes para o movimento da fauna ao longo da paisagem, assim como para a dispersão vegetal. 
A isto, deve-se somar sua função hidrológica na manutenção da integridade física e biológica de uma bacia/microbacia hidrográfica, representada por sua ação direta numa série de processos importantes para a estabilidade, bem como para a manutenção da qualidade/ quantidade de água e para o equilíbrio do próprio ecossistema aquático.

Em alguns locais da área é significativo o florestamento de eucalipto e acácia negra. No local denominado São João, junto a um tributário do arroio de mesmo nome, que se constitui, talvez, na superfície mais degradada da região (conhecido como Deserto), este florestamento atua como barreira à ampliação da degradação nas porções mais à montante.

\section{Hidrografia}

A rede hidrográfica está representada, principalmente, por parte do rio lbicuí, ocupando o norte da área, e pelas bacias dos arroios São João e Divisa, tributários do primeiro.

Segundo Ab Saber (1969) apud Suertegaray, a drenagem do rio lbicuí corta o capeamento arenito basáltico de leste para oeste (acompanhando o mergulho das camadas). Caracteriza-se por ser um rio conseqüente, e a rede de drenagem dos arroios, essencialmente subseqüentes.

O padrão de drenagem é dendrítico, onde ramificações da hidrografia são semelhantes a galhos de árvores, associados a uma topografia relativamente plana. Esse padrão é comum em regiões sedimentares, apresentando a hierarquia fluvial de $6^{a}$ ordem de grandeza.

As drenagens secundárias, como, os arroios Miracatu, São João e Divisa, mostram um controle estrutural apresentando aspecto de encaixe em falha.

Em geral, essas drenagens cortam os sedimentos arenosos e areno conglomeráticos das Seqüências São João e Cerros do Tigre. Por outro lado, o arroio Caraguataí corta além dos sedimentos, rochas vulcânicas da Formação Serra Geral, enquanto que o arroio Lajeado Grande, ao sul da área, inclui em seu encaixe os sedimentos arenosos finos à médios da Formação Botucatu.

\section{Aspectos Erosivos}

A Campanha Gaúcha (AB'SABER, 1969) no oeste-sudoeste do estado, tem na parte pertencente à Depressão Periférica, 
a área mais sujeita a processos de arenização, mais precisamente nos municípios de Alegrete, São Francisco de Assis, Manuel Viana, Itaqui, Cacequi e Quaraí, onde existem milhares de hectares fortemente degradados, que por sua vez estão contidos em uma área maior, de elevada instabilidade física. São áreas, onde o processo de formação dos "campos de areia"(Veiga et alii 1987) / "arenização"(Suertegaray 1987) atuou e continua atuando sobre superfícies planas e dobradas, muitas vezes sobre solos férteis de basaltos presentes na região.

Quanto à origem dos areais, inicialmente, subentendiase que era proveniente da ação antrópica, porém através de estudos e relatos do século passado, verificou-se a existência dos mesmos naquela época, sem que ainda houvesse exploração dos recursos naturais. Contudo hoje as áreas de maior expressão, em hectares, não são mais de origem natural, e sim degradadas pela ação antrópica.

O padrão geológico, entre outros fatores representados, pelas características das litologias, é em suma o grande determinante do padrão erosivo de cada área.

A área situada nos municípios de São Francisco, Manoel Viana e Alegrete são as que menor resistência oferece aos processos erosivos.

O padrão principal é constituído pela erosão em sulco, gerando, normalmente, um padrão ramificado de voçorocamento, que é estabelecido, em geral, sobre a Seqüência São João.

A Seqüência Cerro do Tigre, nesta área, mostra uma maior resistência, freqüentemente retardando o entalhe da vossoroca. Não raro, determinada pela presença de planos de juntas, esta seqüência forma verdadeiros degraus na base do canal, que chegam a atingir 2,5 $\mathrm{m}$ de altura. Nas paredes da vossoroca são detectados processos de erosão interna, o que determina a queda de blocos/ rocha bastante friáveis, para dentro do canal.

Este padrão erosivo é compatível com as características litológicas presentes, visto a alta friabilidade ser responsável pela formação de vários canais. Tal padrão é o mais expressivo em superfície e o principal responsável pelo aparecimento dos grandes campos de areia (Veiga et alii,1987), que tão bem caracterizam a forte degradação ambiental.

\section{APRESENTAÇÃO E ANÁLISE DOS DADOS/RESULTADOS}

Foram enfocados nos dados/resultados os aspectos da degradação ambiental, no que tange às áreas de maior ou menor 
susceptibilidade, bem como os agentes causadores.

São também enfocadas as características sócio-econômicas dos habitantes da área, o ensino de educação ambiental desenvolvido nas escolas trabalhadas, bem como a significação do uso de maquete como instrumento didático no entendimento da problemática ambiental.

Para melhor entendimento das relações existentes entre as características topográficas/tipo de uso de solo/degradação ambiental, leia-se nesta última erosão/assoreamento, confeccionouse uma carta clinográfica de área, onde são mostradas as classes de declividades presentes.

De acordo com De Biase (1992), utilizou-se os seguintes critérios para a definição das diferentes classes de declividade:

- $1^{\text {a }}$ classe, de 0 a $2 \%$ de declividade, foi considerada a área de inundação. Abrange de modo significativo uma larga faixa central que se estende desde o extremo leste da área até o extremo noroeste.

- Envolve as terras planas localizadas às margens do rio Ibicuí e dos arroios Lajeado Grande, São João, Miracatu, Jacaquá e Sanga da Divisa.

- Apresenta terrenos de várzea e zona de inundação, cujas áreas são ocupadas com cultivo de arroz (aptidão natural dos solos, presença de água e topografia que propiciam o cultivo irrigado). A despreocupação com reservas florestais é percebida ao verificar que estas estão restritas às margens dos cursos d'água, em alguns locais as lavouras ocupam até as margens dos mesmos.

- $2^{a}$ classe, de 2 a $5 \%$ de declividade. Este intervalo de declividade distribui-se, praticamente, ao longo de toda área, sobremaneira na porção sudoeste e noroeste. Embora, parte da superfície pertencente a este intervalo possa ser considerada suscetível a processos erosivos, em função das litologias existentes, em especial à sudeste, tais processos são pouco desenvolvidos, por se tratarem de áreas de pouca declividade. Na porção noroeste da carta, onde o tipo rochoso muda de sedimentar arenoso para vulcânico básico, a topografia muda consideravelmente para coxilhas mais alongadas, sem grandes desniveis, o que determina uma maior resistência aos processos erosivos.

- $3^{a}$ classe, de 5 a $12 \%$ de declividade. Com exceção das partes planas que margeiam as drenagens, este padrão de declividade aparece em praticamente toda a área, mais acentuadamente na porção centro-sul e nordeste. Pode ser considerada a área 
onde ocorrem os processos erosivos, favorecidos pelas ca! cas litológicas presentes, que são essencialmente arenosas, com quase total ausência de cimento, o que impõe uma alta permeabilidade.

A restrita cobertura vegetal existente é insuficiente para conter os processos erosivos, desencadeados pelo impacto das chuvas sobre uma cobertura de gramínea não muito densa, intensificada pelo mau uso, através da mecanização agrícola e do superpastoreio.

Nessas vertentes mais íngremes desenvolvem-se erosões internas, que culminam em voçorocas com ramificações, principalmente nas áreas de deságüe de antigas curvas de nível, provocando a instabilidade das vertentes, até mesmo a inutilização de superfícies significativas, algumas maiores que 50 hectares.

- $4^{a}$ classe, com intervalo de 12 a $30 \%$ de declividade. Este intervalo de declividade aparece predominante na porção centro-sul, nordeste e sudoeste da área. Assim como o intervalo anterior, os processos erosivos instalam-se no terço médio a superior das encostas, em especial mais junto ao sopé das maiores declividades.

Além das litologias presentes, a falta de uma vegetação arbórea, bem como, a falta de uma maior densidade de gramíneas, que associadas ao mau uso do solo (lavoura e superpastoreio) propiciam o desencadeamento dos processos de ravinamentos/ voçorocamentos.

- A $5^{a}$ classe, superior a $30 \%$ de declividade, ocupa a porção predominantemente centro-sul da área e alguns pontos da porção centro-norte e oeste.Tratam-se das áreas mais íngremes, pertencentes às encostas dos morros testemunhos. Apesar da grande declividade, os processos erosivos não são significativos, em função da litologia presente, representado por um arenito silicificado com alto grau de cimento silicoso/ferruginoso, formando morros testemunhos, em geral de topo plano e muito resistente aos processos erosivos. Cabe salientar que a grande quantidade de blocos e matacões rochosos de arenito silicificado, que cobrem os flancos destas encostas mais íngremes, às vezes associadas a uma vegetação arbórea de médio porte, são fatores que contribuem e muito, na ação antierosiva.

Decorrem destes processos erosivos, a inutilização de superfícies de terra que embora não muito grandes ( $<50$ há), desenvolve-se com freqüência em inúmeros pontos da área. Estes processos, favorecidos pela retirada das matas ciliares, tornam-se os principais responsáveis pelo assoreamento das drenagens locais, algumas delas, como o Rio Ibicuí, mostrando verdadeiras ilhas atuais. 
Quanto aos aspectos sócio-econômicos dos moradores da área, foram aplicados 25 questionários, dos quais 20 aos pequenos e 5 aos grandes produtores rurais, apesar da população da área distribuir-se de forma rarefeita.

De todos os estabelecimentos visitados, constatou-se que todos eram trabalhados pelos respectivos proprietários. Salienta-se que dois dos grandes produtores rurais, além de proprietários, arrendam terras para cultivo de arroz.

Nas pequenas propriedades, como atividades principais, destacam-se a agricultura e a pecuária. A primeira com produção de milho, melão, mandioca, batata, hortaliça e pastagem, enquanto que a segunda é representada pela criação de bovinos (gado de cria e corte) e ovinos. A criação de suínos e aves, em geral, é pouco representativa.

A produção é, em primeiro lugar, para o consumo próprio, e o excedente comercializado.

Por outro lado, os proprietários rurais com áreas maiores (>500ha), têm sua produção baseada tanto na agricultura, quanto na pecuária, mais raramente em ambas. Aqueles produtores, com terras localizadas nas áreas planas, que margeiam as drenagens, têm sua produção calcada no plantio do arroz irrigado, enquanto os que ocupam áreas de coxilhas, em geral, dedicam-se mais à pecuária extensiva. É importante salientar que embora em um passado recente, essas terras tenham sido utilizadas de maneira indiscriminada para o plantio de soja, hoje, de modo mais sábio, são usadas para o plantio de pastagens, raramente para outro tipo de lavoura.

Apesar dos (grandes e pequenos) produtores preocuparem-se com a alta fragilidade do solo, todos confirmam a utilização da mecanização na lavoura, mesmo aqueles não possuidores de equipamentos. Neste caso, utilizam implementos agrícolas de vizinhos.

Quando questionados sobre a utilização de técnicas de manutenção e conservação do solo nas propriedades, dos 20 pequenos proprietários, 4 fazem rotação de culturas, 6 utilizam curvas de nível e 10 fazem análise de solo. Já os grandes proprietários utilizam o plantio direto, terraceamento, adubação verde e a cada dois anos análise/corretivo de solo.

Quanto ao uso de defensivos agrícola, todos utilizam, seja sob a forma de dessecante, adubo, herbicida ou inseticida. Por existir uma pequena consciência ambiental, que associada a uma falta de programação para seu recolhimento, as embalagens dos 
produtos químicos são, normalmente, enterradas ou queimadas.

No que diz respeito à mão de obra utilizada, nas pequenas propriedades é essencialmente familiar, enquanto que nas grandes propriedades, onde a lavoura de arroz é a atividade primeira, ocorre a contração de terceiros.

No que se refere aos ensinamentos de conteúdos ambientais nas quatro escolas trabalhadas e onde foram aplicados os questionários, pode-se constatar que, com exceção da Escola Estadual de $1^{\circ} \mathrm{Grau}$ Barros Cassal, de Passo Novo, todas possuem um grupo de professores, que organizam suas aulas de forma interdisciplinar, trabalhando com temas do interesse da comunidade escolar. Quanto a atualização sobre a Educação Ambiental, os professores dessas três escolas utilizam jornais, revistas, livros, seminários, documentários e eventuais palestras sobre meio ambiente.

Os projetos e/ou atividades que promovem a Educação Ambiental, são desenvolvidos nas três escolas, desde as séries iniciais do Ensino Fundamental. Eventualmente, os moradores locais, são convidados a participarem de atividades que envolvem desde palestras e campanhas para não jogar lixo nas ruas e estradas, não fazer queimadas de lixo nos quintais, até como evitar o desmatamento. Entre outros, merece destacar o trabalho desenvolvido na Escola Municipal de Ensino Fundamental Costa Leite-Pólo Educacional do Jacaquá, onde, além das atividades normais, há um projeto em prática, que tem como objetivo fixar a população no meio rural, motivando-os através do ensino de técnicas e manejo para maior produção e conservação dos recursos naturais. As principais atividades desenvolvidas são a piscicultura, apicultura, produção em estufas, suinocultura, plantio e colheita de milho, entre outras. Esse trabalho é desenvolvido em propriedades da comunidade local, caracterizando-se pela estreita relação entre a teoria e a prática, bem como a integração escola-comunidade, essencial para o sucesso do projeto.

Todos os professores responderam que é possível desenvolver Educação Ambiental no cotidiano da sala de aula, inclusive, os professores da escola que não organizam suas aulas de forma interdisciplinar, nem desenvolvem nenhum tipo de trabalho relacionado às práticas ambientais.

A partir dos resultados obtidos no trabalho desenvolvido nas escolas, pode-se observar que os alunos que já haviam trabaIhado em sala de aula e/ou em atividades práticas, o tema Educação Ambiental, o desempenho destes foi bastante satisfatório. Tal de- 
sempenho foi manifestado através da participação e questionamentos, tanto no que se refere a palestra ministrada, quanto na construção da maquete. Já na escola onde os alunos não tinham conhecimento sobre o tema e nenhuma professora participou das atividades, a maior parte dos alunos não demonstrou interesse, mostrando-se dispersos e alheios às atividades.

\section{CONCLUSÃO}

A área, objeto deste estudo, insere-se numa área maior, cuja característica física marcante é a alta fragilidade a processos erosivos, especialmente os determinados pela ação das chuvas.

Embora, os processos erosivos naturais sejam efetivos em seu desenvolvimento, a ação antrópica torna-se significativa como fator de aceleração dos mesmos. Tal situação foi marcante no final da década de 60, 70 e início dos anos 80 , com a expansão da lavoura de soja, que culminou, em alguns locais, com a inutilização de amplas superfícies de terra para qualquer tipo de uso, bem como com o grau atual de assoreamento das drenagens locais, neste caso favorecido pela retirada das matas ciliares.

A falta de informações e uso de técnicas inadequadas nas atividades desenvolvidas na área, bem como, agricultura mecanizada e o superpastoreio são desaconselháveis ao tipo de solo, extremamente raso e de alta fragilidade, acelerando o processo e desenvolvimento de ravinas/vossorocas, tornando o produtor rural vítima de suas próprias ações.

A utilização de agrotóxicos nas lavouras, prática confirmada em todas as propriedades entrevistadas, a partir do momento que esses sedimentos são carreados para as drenagens, compromete a qualidade da água e o ecossistema aquático.

Diante da problemática da área, parece pertinente que sejam avaliadas, outras formas de uso do solo. Para tanto, é necessário que haja estudos/esforços na tentativa de descobrir a verdadeira aptidão do mesmo.

Alguns autores sugerem o florestamento através de eucalipto e acácia negra. Para Bellanca e Suertegaray (1998), as espécies mais adaptáveis ao tipo de solo são gramíneas e/ou frutíferas (cítricas).

Enquanto não se encontram alternativas adequadas, faz- 
se mister que a educação ambiental nas escolas seja uma ação contínua, bem como campanhas de conscientização dos moradores locais, com o objetivo de sensibilizar e informar, visando uma tomada de consciência e uma conduta responsável em relação a importância da preservação do meio ambiente na sua utilização, pois o solo e os mananciais de água são os geradores da economia local. 


\section{BIBLIOGRAFIA}

AZEVEDO, A.C \& KAMINSKI, J. Considerações sobre os solos dos campos de areia no Rio Grande do Sul. Ciência \& Ambiente, Santa Maria: UFSM, vol.1, n 1, p. 65-70 (jul) 1990.

BARCELOS, V. H. de L. A Temática Ambiental e a Formação de Professores. Caderno de Pesquisa, n4 , Santa Maria, 1997, $40 \mathrm{p}$.

CUNHA, S.B \& GUERRA, A.J.T. (org ) Geomorfologia do Brasil. Rio de Janeiro: Bertrand Brasil, 1998. p. 192-220.

DE BIASI, M. A Carta Clinográfica: Os Métodos de Representação e sua Confecção. Revista do Departamento de Geografia. USP: $N^{\circ}$ 6, 1992. p. 45-60.

DIRETORIA DO SERVIÇO GEOGRÁFICO. Carta topográfica do município de Manuel Viana: DSG, folha SH. 21-X-D-IV-1, 1978. Escala 1: 50.000 .

DIRETORIA DO SERVIÇO GEOGRÁFICO. Carta topográfica do Distrito de Passo Novo: DSG, folha SH. 21-X-C-VI-2, 1978. Escala 1: 50.000 .

DIRETORIA DO SERVIÇO GEOGRÁFICO. Carta topográfica do município de São Francisco de Assis: DSG, folha SH. 21-X-DIV-2, 1978. Escala 1:50.000.

FENDRICH, R. O; BLADEN, N. L; AISSE, M. M \& GARCIAS, C.M. Drenagem e Controle da Erosão Urbana. $3^{\text {a }}$ ed. São Paulo: IBRASA. Curitiba: CHAMPAGNAT, 1991. p.15-34.

GUERRA, A T. Dicionário Geológico-Geomorfológico. IBGE, 8ª ed. Rio de Janeiro.

KLAMT, E \& SCHNEIDER, P. Solos suscetíveis à erosão eólica e hídrica na região da Campanha do Rio Grande do Sul. Ciência \& Ambiente, Santa Maria: UFSM, vol. 1, n¹, p. 71-80. (jul) 1990.

MACIEL $F^{\circ}$, C. L. Introdução à Geologia de Engenharia. Santa Maria: UFSM, 1994. 284 p.

MARCHIORI, J.N.C. Vegetação e areais no sudoeste riograndense. Ciência \& Ambiente, Santa Maria. UFSM, vol. 1, n¹, p.81-92 ( jul )1990.

MEDEIROS, E.R. Estratigrafia do Grupo São Bento na região de Santa Maria e paleocorrentes da Formação Botucatu. Porto Alegre, UFRGS-IG,1980.135p. (Dissertação de Mestrado).

MEDEIROS, E.R; ROBAINA, L.E.S . Degradação ambiental na região centro oeste do Rio Grande do Sul. Ciência \& Ambiente, 
Santa Maria: UFSM.vol. 1, n¹, p.53-64 ( jul )1990.

MENDONÇA, F.A. Geografia e meio ambiente. São Paulo: Contexto, 1993. (coleção caminhos da geografia)p.55-74.

NOVA ESCOLA, A Revista do Ensino Fundamental, PCN. Base para Debater Questões Ambientais. ANO XIV N 125 - Setembro, 1999 p. 35.

REIGOTA, M. Meio Ambiente e Representação Social. Questões da Nossa Época, ed, 41, São Paulo: Cortez, 1995, p. 87.

RODRIGUES, R. R \& LEITÃO $F^{\circ}, H$. F. Matas Ciliares: Conservação e Recuperação. São Paulo: USP: Fapesp, 2000. p 33-44.

SUERTEGARAY, D.M.A Deserto Grande do Sul: Controvérsia. 2. ed. Porto Alegre: UFRGS, 1998.

VEIGA, P; MEDEIROS, E, R. Gênese dos Campos de Areia no Município de Quaraí-RS In Anais do I Congresso da Associação Brasileira de Estudos do Quaternário. Porto Alegre: UFRGS, 1987.

VIEIRA, E. F. Rio Grande do Sul: Geografia física e vegetação Porto Alegre: Sagra, 1984. 184p.

JaQueline Flain Moraes Pós-Graduanda em Educação Ambiental

Centro de Ciências Rurais

Edgardo Ramos Medeiros

Departamento de Geociências Centro de Ciências Naturais e Exatas Universidade Federal de Santa Maria

Santa Maria, RS - Brasil 